\title{
Heating Mechanism in the Electrical Joining Process of $\mathrm{Si}_{3} \mathrm{~N}_{4}$ Ceramics
}

\author{
Koji OKUDA, Hiroshi TAKAI, Tokumitsu NISHI and Hiroaki YANAGIDA* \\ DAIHEN Corporation, 2-1-11, Tagawa, Yodogawa-ku, Osaka-shi 532 \\ *Department of Industrial Chemistry, Faculty of Engineering, The University of Tokyo, 7-3-1, Hongo, Bunkyo-ku, Tokyo \\ 窒化ケイ素セラミックスの電気接合プロセスにおける加熱メカニズム \\ 奥田浩司・高井博史・西 徳三・柳田博明* \\ (株) ダイヘン, 532 大阪市淀川区田川 2-1-11 \\ *東京大学工学部工業化学科, 113 東京都文京区本郷 7-3-1
}

[Received January 13, 1993, Accepted March 16, 1993]

\begin{abstract}
The electrical joining of $\mathrm{Si}_{3} \mathrm{~N}_{4}$ ceramics using a local heating system was studied to clarify the relevant heating mechanism. In this study, a $\mathrm{CaF}_{2} / \mathrm{kaolinite} \mathrm{mixture}^{2}$ with suitable electroheating characteristics and good reactivity with $\mathrm{Si}_{3} \mathrm{~N}_{4}$ ceramics was used as a joining agent. The temperature characteristics of conductivity of the joining agent, the electrical characteristics during electroheating and the composition of the joint layer were examined. The heating process in this joining method consisted of preheating by a gas flame and principal heating by electroheating. The electrical conduction of the joining agent was due to ionic conduction of $\mathrm{CaF}_{2}$ and the conductivity was enhanced by preheating. Starting electrical charging to the joining agent, joule heat was generated and the entire joining plane was heated to high temperature by the self-controlling mechanism arising from changes in the composition of the joining agent. In addition, the maximum temperature in the joining plane was estimated about $1800^{\circ} \mathrm{C}$ by thermal conduction analysis.
\end{abstract}

Key-words : $\mathrm{Si}_{3} \mathrm{~N}_{4}$ ceramics, Electrical joining process, Heating mechanism, Joule heating, Self-controllability

\section{Introduction}

The urgent development of ceramics joining technologies has been desired for extensive uses in structual applications of ceramics. A variety of joining methods are currently under consideration. ${ }^{1)}$ Nearly all of the present methods, however, consist of a whole heating system, wherein the ceramics parts to be joined are placed entirely within a high-temperature furnace. For joining large or long parts, the lack of proper plant equipment or deterioration of parent material constitutes a problem for this method. Therefore, a local heating system, which permits heating of mainly the portion to be joined, seems preferable. The present authors have researched such a local heating system-that is, an electrical joining method that uses direct heating by electrical charging and can join ceramics parts even in air. ${ }^{2)-4)}$

With the present electrical joining method, the joining agent itself is electrically charged, so that any joining agent used must be reactive with ceram- ics and at least be electroconductive at high temperature. A variety of joining agents were investigated for the present study, including those containing a substance that is electroconductive even at room temperature, like metals, and those containing oxides and/or fluorides that acquire electroconductivity at high temperatures. These studies indicated that a joining agent containing $\mathrm{CaF}_{2}$ had suitable electroheating characteristics, but the heating mechanism in the present joining method has not yet been clarified. Generally, a heating is an important process in the joining of ceramics. In particular, the heating conditions influence greatly the performance of the joint, when joining is accomplished by a local heating system such as the electrical joining method.

The heating process in the electrical joining method can be subdivided roughly into two steps: (1) preheating, by a gas flame, and (2) principal heating, by electroheating. Preheating reduces thermal shock during electroheating and increases the electroconductivity of the joining agent. Thermal shock can result when abrupt heating from electrical charging in a domain several hundreds of micrometers in size, corresponding to the thickness of the joining agent, subjects the ceramic parent material near the joint to a large thermal gradient, causing cracks in the ceramic parent material. Preheating the ceramic parent material can alleviate thermal shock during electroheating. Preheating is particularly imperative for a material such as $\mathrm{Al}_{2} \mathrm{O}_{3}$, which is highly susceptible to thermal shock. The mixture of $\mathrm{CaF}_{2} /$ kaolinite used as a joining agent in the present study possesses high electrical resistance at room temperature, so that heating the mixture by electroheating alone was not feasible with the present equipment (maximum voltage of $6600 \mathrm{~V}$ ). Preheating the mixture to above 700 to $800^{\circ} \mathrm{C}$ with a gas flame, however, reduced the electrical resistance of the mixture, permitting electroheating. After preheating and initiation of electrical charging, the joining portion was heated rapidly; the joining agent thus melted and reacted with the ceramic materials.

At first, we thought that it seemed best to join the 
ceramics by heating the entire joining plane through the movement of rod electrodes along the joining portion, but we were afraid that the current pathway might not move following the movement of electrodes because the conductivity of the joining agent increased with a rise in temperature. Since the resistance of the joining agent in the current pathway formed by electrical charging would decrease with a rise in temperature, it was thought that the current pathway would not be able to move from that portion to another even if electrodes were moved. As a matter of fact, however, the current pathway apparently moved in conformity with the movement of the rod electrodes, and a joining of the entire joining plane $(15 \mathrm{~mm} \times 15 \mathrm{~mm})$ was accomplished.

Clarifying the heating mechanism during electroheating, so as to understand how the current pathway forms and moves within the joining plane, is imperative to improving the heating state at the joining portion, to further research on the newly developed joining agents, and also to enhance the joining performance. The present paper reports results of research on the heating mechanism in the electrical joining of $\mathrm{Si}_{3} \mathrm{~N}_{4}$ ceramics, using a mixture of $\mathrm{CaF}_{2} /$ kaolinite $(70 / 30 \mathrm{wt} \%)$ as the joining agent. This mixture is proved to have good electroheating characteristics, as well as a four-point bending strength of $\sim 300$ $\mathrm{MPa}$ over a temperature range from normal room temperature to $800^{\circ} \mathrm{C}$.

\section{Experimental procedure}

Figure 1 shows a compositional drawing of the equipment used in the present study. This joining equipment consisted of upper and lower fixing systems for holding the sample piece, a gas flame nozzle, a gas flow-rate regulating system, electrodes, a travel system for the electrodes, a power supply unit for heating, and various kinds of measuring devices. Tungsten bars of $2.0 \mathrm{~mm}$ in diameter were used as the electrodes. As the heating power supply, a $60 \mathrm{~Hz}$ high-voltage power supply having drooping characteristic (maximum voltage of $6600 \mathrm{~V}$, maximum cur-

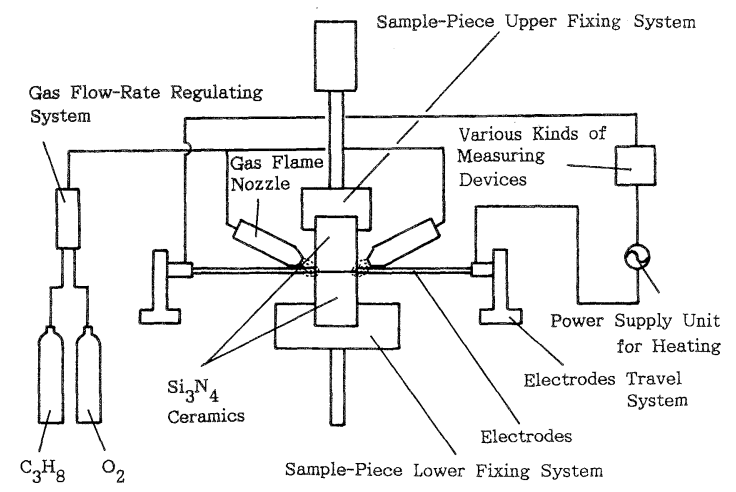

Fig. 1. Composition drawing of the equipment used in electrical joining method. rent of $2.0 \mathrm{~A}$, produced by Daihen Corporation) was used to prevent damage in the sample piece or power supply due to the abrupt increase in current. A mixture gas of propane and oxygen was used as the preheating gas. The ceramics to be joined were blockshaped pieces $(15 \mathrm{~mm} \times 15 \mathrm{~mm} \times 20 \mathrm{~mm}$ in size $(15$ $\mathrm{mm} \times 15 \mathrm{~mm}$ of joining plane)) of $\mathrm{Si}_{3} \mathrm{~N}_{4}$ prepared by normal pressure sintering (doped $\mathrm{Y}_{2} \mathrm{O}_{3}$ and $\mathrm{Al}_{2} \mathrm{O}_{3}$ as sintering aids). The surface roughness of the joining plane was $<2 \mu \mathrm{m}$ at $R_{\max }$. For the joining agent, a mixture of $\mathrm{CaF}_{2} /$ kaolinite $(70 / 30 \mathrm{wt} \%)$ was prepared and ground consecutively for $24 \mathrm{~h}$ using a ball mill, and a binder then added to create a pastelike joining agent ready for use.

Figures 2 and 3 show respectively the basic joining process and heating profile in the electrical joining method. The joining was accomplished as follows,

(a) Each joining plane of the ceramics to be joined was screen-printed uniformly with the pastelike joining agent.

(b) The planes were butted to each other and set on the fixing jig provided in the joining equipment.

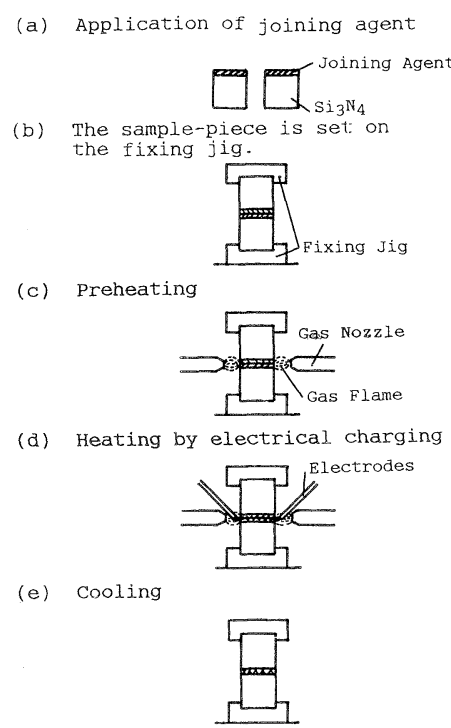

Fig. 2. Basic joining process in electrical joining method.

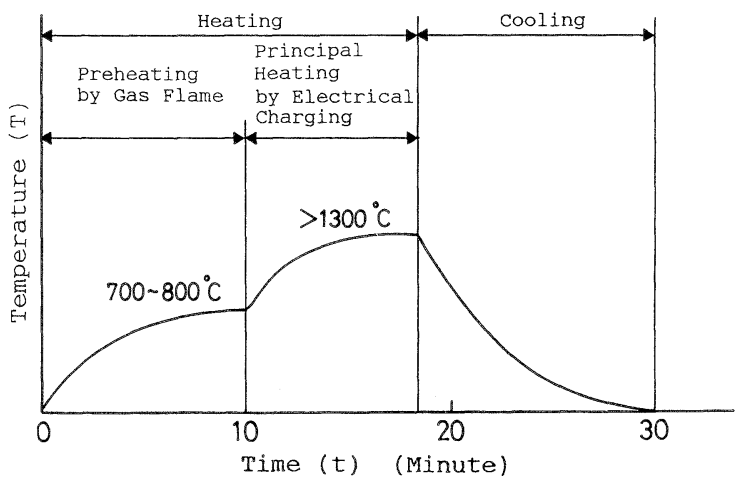

Fig. 3. Basic heating profile in electrical joining method. 
(c) The joining portion was preheated with a propane gas flame to 700 to $800^{\circ} \mathrm{C}$.

(d) After the temperature ascent of $\mathrm{Si}_{3} \mathrm{~N}_{4}$ has saturated, the electrical charging to the joining agent was initiated to heat the joining portion by electroheating. The electrodes were installed on a structure capable of contacting the joining portion of $\mathrm{Si}_{3} \mathrm{~N}_{4}$ and exercising a reciprocating motion in the direction of the joining length, in compliance with a variable pattern. The entire joining plane was heated to a specified temperature by controlling the moving pattern of the electrodes, electric current value and electroheating time. As a result, the joining agent was molten and had reacted with the ceramics.

(e) The sample pieces were cooled to room temperature, and joining was completed.

The entire process was conducted in air environment.

To verify changes in the conductivity of the joining agent with temperature, the conductivity was measured in steps from the powder state to that of a molten liquid. The powdered joining agent was measured in air environment using the complex impedance method from room temperature to $1200^{\circ} \mathrm{C}$, after the powdered joining agent had been placed between parallel plane Pt electrodes and set on an $\mathrm{Al}_{2} \mathrm{O}_{3}$ jig. Conductivity after melting of the joining agent was also determined by using the two-terminal method and by measuring the corresponding impedance at each temperature. After the powdered joining agent had been placed in a Pt crucible and heated to a molten state within a high-temperature furnace in air environment, the Pt electrodes, provided on a lifting device, were dipped into the molten liquid to a depth of $10 \mathrm{~mm}$. Measurements were made from 1300 to $1500^{\circ} \mathrm{C}$, and the cell constant and conductivity were calculated according to the methods specified by Ueda et al. . $^{\text {) }}$

The voltage waveform and Lissajous figure during electroheating were observed by synchroscope and voltage $(V) /$ current $(I)$-to-time curves were measured by power meter and recorder at the same time. Resistance $(R)$-to-time curve was obtained by calculating from Ohm's low $(R=V / I)$, using abovemeasured voltage values $(V)$ and current values $(I)$. To explain the variation in resistance during electroheating, the state of diffusion of elements and the composition in the joint layer were investigated by electron probe microanalysis (EPMA).

Furthermore, the movement of the current pathway within the joining plane was also observed directly using a transparent sapphire as a substitute for the upper $\mathrm{Si}_{3} \mathrm{~N}_{4}$ sample piece.

Finally, the temperature distribution of the joining sample was examined by thermal conduction analysis in unsteady-state, using the finite element method. Characteristic values of $\mathrm{Si}_{3} \mathrm{~N}_{4}$ ceramics, boundary conditions of $\mathrm{Si}_{3} \mathrm{~N}_{4}$ surface and heat quantity given by electroheating were given as the input conditions for this analysis. Values from the catalog data were used as characteristic values of $\mathrm{Si}_{3} \mathrm{~N}_{4}$ ceramics such as specific heat, thermal conductance and density. The measured values by a thermocouple were used as environmental temperatures that were one of boundary conditions. The calculated values from electric power, which had been measured by power meter during electroheating, were used as heat quantity given by electroheating. On the assumption that the heat quantity was given in the current pathway of $2.5 \mathrm{~mm}$ in width by $600 \mu \mathrm{m}$ in thickness by $15 \mathrm{~mm}$ in length, calculations by a computer were carried out repeatedly, altering input data on a coefficient of heat-transfer, so as to agree nearly with the measured temperature of the sample surface by an optical thermometer.

\section{Results and discussion}

To clarify the effect of preheating, the temperature characteristics of conductivity in the powdered state of a joining agent were examined. The results of the present study are shown in Fig. 4. Joining agents with three different compositional ratios exhibit the same positive relation that the conductivities increase exponentially with temperature, as shown by the straight lines with similar slopes in Arrhenius plots, whatever the compositional ratios. The activation energies, calculated from the slopes of the lines, were $\sim 0.86 \mathrm{eV}$. Because the activation energies are equivalent for both $100 \mathrm{wt} \% \mathrm{CaF}_{2}$ and mixtures of $\mathrm{CaF}_{2} /$ kaolinite, the electrical conduction of the joining agent seems to be due to ionic conduction of $\mathrm{CaF}_{2}$ known as a good ionic conductor. The mixture of $\mathrm{CaF}_{2} /$ kaolinite $(70 / 30 \mathrm{wt} \%)$ had a greater conductivity than the $\mathrm{CaF}_{2}(100 \mathrm{wt} \%)$, possibly because a more electroconductive layer formed in the boundary between the $\mathrm{CaF}_{2}$ and the kaolinite. ${ }^{6)}$ It was comfirmed that the conductivity of the joining agent increased remarkably by preheating to $\sim 700$ to $800^{\circ} \mathrm{C}$, as expected.

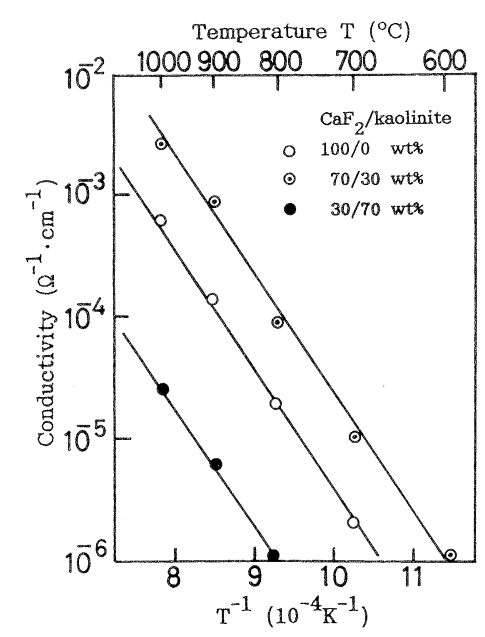

Fig. 4. Temperature characteristics of conductivity of joining agents in powdered state. 
The heating mechanism during electroheating was also examined. Figure 5 shows a voltage waveform (a) and a Lissajous figure (b) obtained during electroheating with the electrodes brought into close contact with the joining portion. Since the voltage waveform is a sinusoidal wave that matches that of the power source, and also because the Lissajous figure presents a straight line with a slope of $\sim 45^{\circ}$, it can be safely affirmed that the heat generated during electroheating is joule heat caused mainly by pure electric resistance (i.e., resistance of the joining agent).

Figure 6 shows the electrical characteristics during electroheating; load voltage $(V)$ /load current $(I)$-time curve (a), and resistance $(R)$-time curve (b). When the power supply voltage is increased at a constant speed, a small current $\left(I_{\mathrm{s}}\right)$ (hereafter called precursory current) flows initially, increasing with voltage; then, at a certain voltage, the current $(I)$ increases abruptly while at the same time load voltage $(V)$ shows a rapid decrease. After that rapid decrease, the load voltage increases gradually in the domain where the current became constant. If, however, the contact between the electrodes and the joining portion is somewhat defective, the precursory current is not clearly observed; in its place, a minute aerial discharge occurs at a certain voltage, creating an instantaneous transition to the current
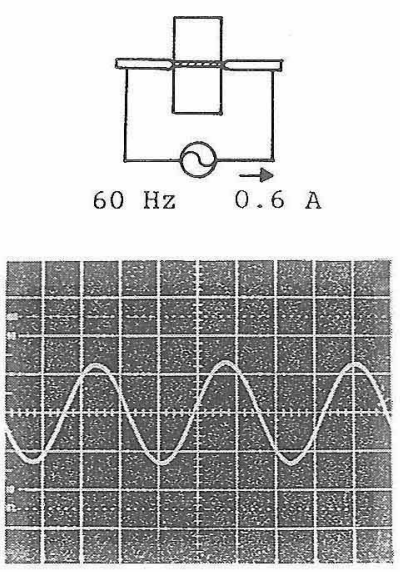

(a) Load Voltage Waveform

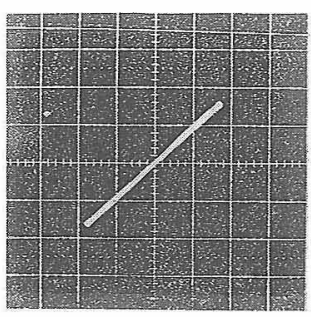

(b) Lissajous Figure

Fig. 5. Voltage waveform (a) and Lissajous figure (b) obtained during electroheating with electrodes brought into contact closely with joining portion. rapid increment zone. Accordingly, the maximum voltage at which the current increases abruptly will hereafter be called the starting voltage. Such changes in current and voltage seem to be caused by changes in the resistance of the joining agent, and these changes comprise three zones or domains: the gradual decrease in resistance zone I, in the initial stage; the abrupt decrease in resistance zone II; and the gradual increase in resistance zone III, in the final stage.

To explain such changes in resistance, conductivity of the joining agent was measured after melting it. The results are shown in Fig. 7, along with conductivity for the joining agent in the powdered state. In the melted state also, the conductivity of the joining agent increased exponentially with temperature, just

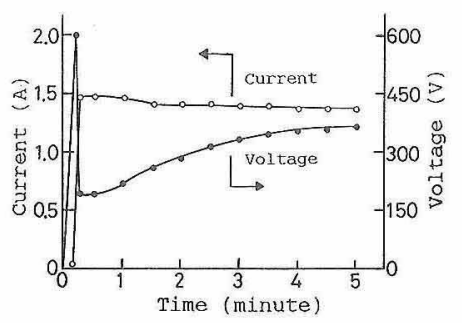

(a) Current/Voltage-Time Curve

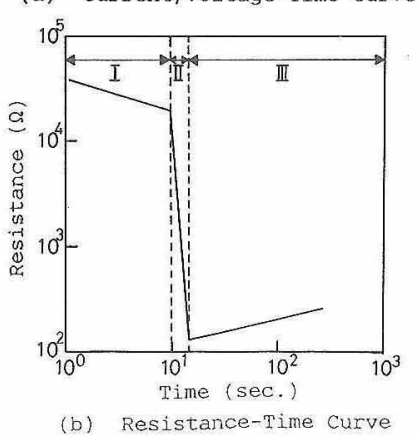

Fig. 6. Electrical characteristics during electroheating in $\mathrm{Si}_{3} \mathrm{~N}_{4}$ joining process.

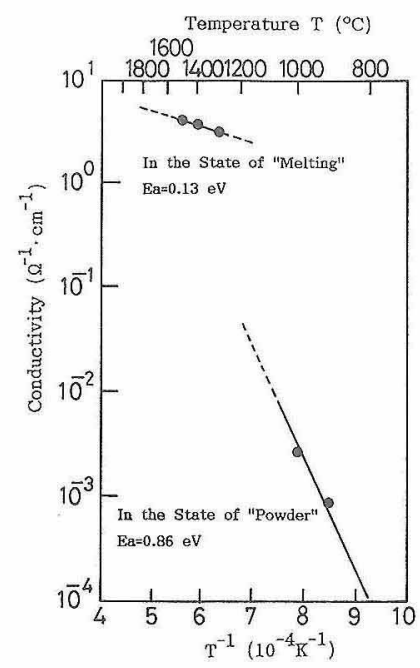

Fig. 7. Temperature characteristics of conductivity of $\mathrm{CaF}_{2} /$ kaolinite $(70 / 30 \mathrm{wt} \%)$ joining agent in powdered and melted states. 
as in the powdered state, showing an approximately linear curve in Arrhenius plots. The activation energy calculated from the slope of the straight line was $\sim 0.13 \mathrm{eV}$. Moreover, conductivity clearly increased abruptly at the point of transition from the solid to the liquid phase. This abrupt increase apparently seems to be caused by the sudden disappearance of the contact resistance between particles of the joining agent.

The above-mentioned results make it possible to discuss separately the heating mechanism acting on the first and second zones in the change of resistance, shown in Fig. 6(b): First, when the preheating temperature is 700 to $800^{\circ} \mathrm{C}$, a precursory current $\left(I_{\mathrm{s}}\right)$, in proportion to the increased power source voltage, flows because the resistance of the joining agent is still high. Joule heat generated by the current and the resistance of the joining agent makes the temperature of the joining agent in that portion rise. The resistance value of the joining agent thus decreases, causing the precursory current $\left(I_{\mathrm{s}}\right)$ to increase. As this process is repeated, the temperature of the joining agent increases step by step, but the resistance of the joining agent decreases, in inverse proportion (zone I). As temperature rises further, so that the temperature of a part of the joining agent reaches its melting point, resistance begins to decrease abruptly with rapid current increase. A large amount of joule heat is generated, the molten area expands, and rapid decrease is observed in the resistance value (zone II). Therefore, if preheating temperature is constant and the melting point the same, lower resistance of the joining agent results in lower starting voltage. When the joining agents have similar resistance values, lower melting point results in lower starting voltage.

The gradual increase in zone III of the resistancetime curve cannot be fully explained, because based on the results obtained so far, the resistance of the joining agent should decrease with rising temperature in the molten state also.

In the resistance formula, $R=\rho(l / s)$, changes in the portion corresponding to the shape factor, $l / s$, could not yet be defined for lack of measurements, so that the change in resistivity, $\rho$, was next examined. The change in the resistivity might be explained by changes of substance from the initial composition of the joining agent. Thus, the composition of the joint layer was investigated by EPMA and was compared with the initial composition of the joining agent. The results obtained are shown in Table 1 . As revealed in Table 1, there was a considerable decrease in the quantity of the elements $\mathrm{Ca}$ and $\mathrm{F}$ that seemed to be the major carriers for ionic conduction of the joining agent.

An EPMA line analysis also was conducted vertically to the joint layer on the joined sample, and the result is shown in Fig. 8. These results indicated that the reduced quantity of Ca was caused by diffusion of $\mathrm{Ca}$ into the $\mathrm{Si}_{3} \mathrm{~N}_{4}$ ceramics. Since no diffusion of $\mathrm{F}$ into the $\mathrm{Si}_{3} \mathrm{~N}_{4}$ ceramics was observed, it was suspected the reduced quantity of $\mathrm{F}$ was caused by evaporation of $\mathrm{F}$ through a series of more complicated reactions, for instance, those indicated in the following formulas. Equation (1) represents the reaction between $\mathrm{CaF}_{2}$ in the joining agent and $\mathrm{SiO}_{2}$ in the joining agent and/or from $\mathrm{Si}_{3} \mathrm{~N}_{4}$ ceramics, Eq. (2) that between $\mathrm{CaF}_{2}$ in the joining agent and $\mathrm{O}_{2}$ in air, and Eq. (3) the reaction with $\mathrm{H}_{2} \mathrm{O}$ produced by the decomposition of the gas flame.

$$
\begin{aligned}
& 2 \mathrm{CaF}_{2}+\mathrm{SiO}_{2} \rightarrow 2 \mathrm{CaO}+\mathrm{SiF}_{4}(\mathrm{~g}) \uparrow \\
& 2 \mathrm{CaF}_{2}+\mathrm{O}_{2} \rightarrow 2 \mathrm{CaO}+2 \mathrm{~F}_{2}(\mathrm{~g}) \uparrow \\
& \mathrm{CaF}_{2}+\mathrm{H}_{2} \mathrm{O} \rightarrow \mathrm{CaO}+2 \mathrm{HF}(\mathrm{g}) \uparrow
\end{aligned}
$$

The reduction of $\mathrm{Ca}$ and $\mathrm{F}$ causes not only a decrease in the number of carriers for ionic conduction, but also a decrease in the mobility of the carrier due to an increase in the viscosity of the molten joining agent, thus causing an increase in resistivity. Therefore, zone III in the resistance-time curve shown in Fig. 6(b) apparently exists because the increases in resistance resulting from compositional changes of the joint layer following reactions of the joining agent dominate decreases in resistance caused by rising temperature.

The moving mechanism of the current pathway, a suspected problem from the beginning of the present study, can be explained from the above-mentioned changes in resistance as well. Since the resistance of the joining agent at the current pathway did increase through changes in the composition following reactions of the joining agent, the current pathway could

Table 1. Comparison of $\mathrm{Ca}$ and $\mathrm{F}$ contents in the joint layer with those in the initial joining agent.

\begin{tabular}{|c|c|c|}
\hline Element & $\begin{array}{l}\text { Joining agent } \\
\text { initially used }\end{array}$ & $\begin{array}{l}\text { Joint layer } \\
\text { finally obtained }\end{array}$ \\
\hline $\mathrm{F}$ & 35.8 & 0.4 \\
\hline $\mathrm{Ca}$ & 37.8 & 18.5 \\
\hline
\end{tabular}

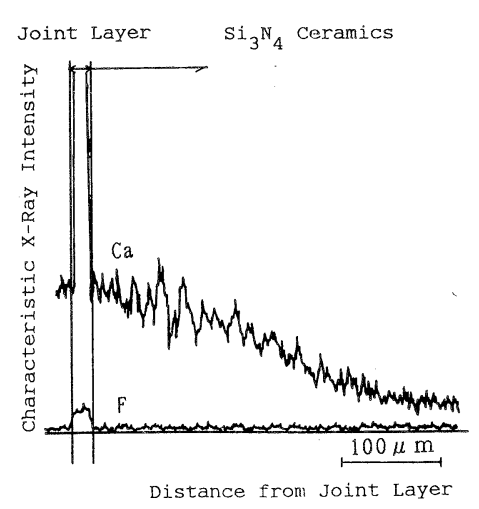

Fig. 8. Distributions of $\mathrm{Ca}$ and $\mathrm{F}$ in the vertical direction to the joint layer of $\mathrm{Si}_{3} \mathrm{~N}_{4}-\mathrm{Si}_{3} \mathrm{~N}_{4}$ joined sample. 
move successively toward a newer, unreacted portion of the joining agent with lower resistance, in conformity with the movement of the electrodes. In other words, this mechanism can be considered selfcontrolling, because the current pathway itself is able to move, without any other external force and in a natural manner, toward a portion with lower resistance and easier flow of the joining agent; ultimately, when the movement of the current pathway is no longer possible because of increased resistance through changes in the composition of the joining agent, all of the reactions required for the joining process will have proceeded sufficiently. For instance, the current pathway could move naturally across a considerable area of the joining plane even if electrodes were fixed at the center of the joining portion. The method moving electrode, however, is normally used for joining because more reliable joining can be performed. In this latter case, the ability that the current pathway can pursue, or follow the electrode movement is influenced by electrode moving speed. The uniform temperature in the joining plane seems to favor a rapid electrode moving speed. In practice, however, too rapid an electrode moving speed $(30 \mathrm{~mm} / \mathrm{s})$ can prevent the current pathway from moving far enough from the center, so that good heating is impossible. Since the optimum electrode moving speed depends on the speed with which the composition of the joining agent changes, it is influenced by the kind of joining agent, the preheating temperature and the electrical current value for heating. In this system, good following property to electrode movement was obtained by applying a moving speed of $\sim 1 \mathrm{~mm} / \mathrm{s}$.

To observe actually the movement of the current pathway in the interior of the joining portion, the upper sample piece, made of $\mathrm{Si}_{3} \mathrm{~N}_{4}$, was exchanged for one made of transparent sapphire. Although the exchange for sapphire might cause some different states from those of the original piece: which, for example, might cause some cracking in sapphire body because of thermal shock by electrical charging and also might produce a different series of reactions with the joining agent, the movement of current pathway could be observed as expected. The current pathway moved from one portion to the other, following the movement of the electrodes, although with a slight time lag.

The movement of the current pathway is induced by increasing the resistance caused by the reaction of the joining agent at the current pathway, and larger change in resistance will make the movement of current pathway easier. Uniform heating necessitates the selection of a joining agent with good following abilities and optimization of the electrode moving pattern in accordance with these abilities.

It is also important during electroheating to know the accurate temperature in the joining plane. Actual- ly measuring the temperature by using a thermocouple often is impractical because of the high voltage applied at the time of joining. A noncontacting type of thermometer such as an optical thermometer is much more efficient, but the thermometer measures only surface temperature, so that the temperature of the most important portion - the interior of the joint - cannot be measured at all. The temperature distribution of the sample piece including the interior of the joining portion was calculated by thermal conduction analysis using the finite element method. As a result of this analysis, a maximum temperature in the joining plane during electroheating was estimated about $1800^{\circ} \mathrm{C}$. This calculated temperature is over the decomposition temperature of $\mathrm{Si}_{3} \mathrm{~N}_{4}$. Since a few grains of $\beta-\mathrm{Si}_{3} \mathrm{~N}_{4}$, which seem to be mixed from the joint layer, can be found practically in the joint layer, it is thought that the joining plane will become a considerably high temperature during electroheating.

\section{Conclusions}

The electrical joining of $\mathrm{Si}_{3} \mathrm{~N}_{4}$ ceramics using a local heating system was examined with a mixture of $\mathrm{CaF}_{2} /$ kaolinite as the joining agent to clarify the heating mechanism, which is considered one of the most important aspects of this joining process. The heating process in this joining method consisted of two subprocesses: (1) preheating, accomplished by means of a gas flame, and (2) principal heating, accomplished by means of electroheating. Preheating not only made a thermal shock lessen, but also made the electroconductivity of the joining agent with ionic conduction increase so as to make possible the subsequent electroheating. Principal heating, which was the electroheating used joule heat generated in the joining agent, heated the joining portion to high temperature over the melting point of the joining agent and made it react with $\mathrm{Si}_{3} \mathrm{~N}_{4}$ ceramics. During electroheating, since the self-controllability of the joining agent enabled the current pathway to move from one position to another along the joining plane, the entire joining plane could be heated to high temperature by means of moving electrodes. It was found that this self-controllability was produced by the increased resistance due to changes in the composition of the joining agent and played an important part in this heating process. In addition, the maximum temperature in the joining plane after these heating process was estimated about $1800^{\circ} \mathrm{C}$ by thermal conduction analysis.

In order to accomplish the efficient joining of $\mathrm{Si}_{3} \mathrm{~N}_{4}$ ceramics using the present joining method, the present results indicated that it was important to select the joining agent with suitable electroconductivity and self-controllability in addition to the good reactivity with ceramics, and to optimize joining conditions such as preheating temperature, electric cur- 
rent value and electrode moving speed, in accordance with the self-controllability of the joining agent.

\section{References}

1) H. Takasio, Kogyo-Zairyo, 33, 116-23 (1983).

2) M. Kohyama, T. Nishi, N. Tamari, M. Kinoshita and Y. Ebata, Yogyo-Kyokai-Shi, 94, 1197-200 (1986).

3) K. Okuda, T. Nishi, N. Miyake, N. Tamari, T. Kawamoto and Y. Ebata, Proc. Fall Meeting of The Ceram. Soc. of Japan (1988) pp. 467-68.

4) Y. Ebata, M. Kohyama, M. Iwasa, M. Kinoshita, K. Okuda, H. Takai and T. Nishi, Seramikkusu Ronbunshi, 97, 88--90 (1989).

5) K. Ueda, S. Doi and A. Kondo, Memories of the Ehime University, Sect. III (Engineering), 9, 773-80 (1980).

6) S. Fujitsu, M. Miyayama, K. Koumoto, H. Yanagida and T. Kanazawa, J. Mater. Sci., 20, 2103-09 (1985). 